\title{
RESULTS OF A STUDY OF THE AMMONIA ABSORPTION EFFICIENCY BY A BRINE IN A VORTEX DEVICE
}

\author{
Alina Hrubnik ${ }^{1}$, Tetiana Novozhylova ${ }^{2}$, Evgeny Semenov ${ }^{3}$ \\ ${ }^{1}$ Department of chemical technique and industrial ecology, National Technical University «Kharkiv Polytechnic Institute», Kharkiv, \\ Ukraine \\ alina.hrubnik@gmail.com \\ ORCID: http://orcid.org/0000-0002-8561-5682 \\ ${ }^{2}$ Department of chemical technique and industrial ecology, National Technical University «Kharkiv Polytechnic Institute», Kharkiv, \\ Ukraine \\ ORCID: http://orcid.org/0000-0003-2551-6954 \\ ${ }^{3}$ Department of labor and environment protection, National Technical University «Kharkiv Polytechnic Institute», Kharkiv, Ukraine \\ ORCID: http://orcid.org/0000-0001-9280-947X
}

ARTICLE INFO

ABSTRACT

Article history:

Received date 18.03.2020

Accepted date 14.04.2020

Object of research: vortex mass transfer device for the effective absorption of ammonia

Published date 30.04.2020

by brine in soda production.

Section:

Industrial ecology

Investigated problem: intensification of mass transfer processes and ensuring effective absorption of ammonia with small dimensions of the device and low hydraulic resistance Main scientific results: studies of ammonia absorption efficiency in a laboratory device

D O I are carried out, which confirm the operability of the proposed device design. The dependences of the efficiency of the vortex device on the ammonia concentration and the brine consumption are revealed. The flow velocity and pressure in the device are simulated at various capacities.

KEYWORDS

Scope of practical use of the research results: the research results can be used in the

vortex device

ammonia absorption

carbonization stage emissions

swirler

flow modeling design of mass transfer equipment, primarily equipment for purifying emissions from ammonia and gas breakers from soda ash columns.

Innovative technological product: the design of the vortex device, which allows achieving a high degree of absorption in ammonia with a concentration of up to $130 \mathrm{~g} / \mathrm{m}^{3}$ of the order of $99 \%$ at low operational (due to low hydraulic resistance) and capital (due to the compactness and small size of the installation) costs.

Scope of the innovative technological product: the vortex device of the proposed design can be used to clean emissions, absorption of ammonia vapor or other mass transfer processes.

(C) The Author(s) 2020. This is an open access article under the CC BY license http://creativecommons.org/licenses/by/4.0).

\section{Introduction}

\section{1. The object of research} fer device.

The object of research is the process of ammonia absorption by brine in a vortex mass trans-

\section{2. Problem description}

The modern production of soda ash by the ammonia method has a high level of technology organization, which is based on the continuity and automation of production. However, unlike others, the modern powerful production of soda ash is characterized by extremely high material consumption of equipment and large environmental pollution [1-3], the amount of which in absolute terms of waste per year exceeds the waste of many chemical plants by tens of times.

Despite the fact that the most common ammonia method for producing soda ash has existed for more than a hundred years, issues related to reducing the resource consumption of the process, achieving optimal utilization rates of raw materials and protecting the environment have not been completely resolved today [2, 4]. However, some of these problems can be eliminated by improving technological processes and modernizing existing equipment. It is known that the total mass of ammonia circulating in the production of soda by the ammonia method is about $530 \mathrm{~kg}$ per 1 ton of soda, some of which is lost due to imperfection of ammonia desorption processes [4]. However, 
the main source of gas emissions of ammonia and carbon dioxide in the production of soda ash is the carbonization process $[2,5]$.

The basic principle of operation of existing mass transfer device in the production of soda is the bubble principle. Cast iron is used as the main material for the manufacture of device. To clean the device from salt deposits, their industrial steps are made large and accessible so that a person can climb inside the device. Due to the large diameter of the equipment and the large number of stages with heat exchange surfaces, the total material consumption of the column equipment for the production of soda ash in a single plant reaches more than ten thousand tons.

Thus, in addition to environmental problems, in the technology for the production of soda ash there are large capital costs for equipment. The large material consumption of equipment technology soda ash currently holds back the subsequent pace of intensification of production.

\section{3. Suggested solution to the problem}

After analyzing the known designs of heat and mass transfer devices and contact devices [6, 7], the task is to develop and justify a promising design of a highly efficient contact device that provides increased gas and liquid throughput with the least hydraulic resistance. A promising direction in the field of intensification of ammonia absorption processes are vortex devices [8]. The organization of the vortex of countercurrent gas and liquid droplets in them makes it possible to achieve a change in concentration in one spray stage, which corresponds to several theoretical stages of concentration change [9]. This is explained both by the presence of a developed interphase surface and by the turbulization of internal circulating currents in drops, which leads to a more intensive updating of the interphase surface of drops [10] and accelerates mass transfer processes.

Therefore, the search for new highly effective contact and at the same time small-sized devices is an urgent directional research.

\section{Materials and Methods}

A study of the effectiveness of the developed vortex contact device was carried out in a laboratory device, shown in Fig. 1.
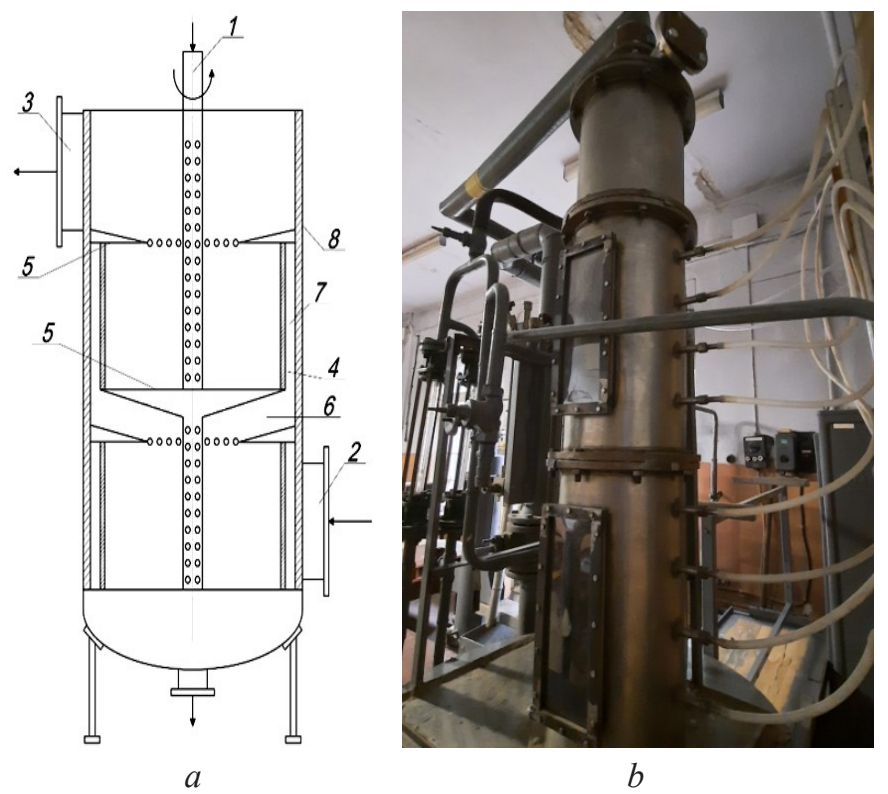

Fig. 1. Laboratory device for studying the absorption process: $a$-scheme; $b$-photo of the experimental device; 1 - liquid sprinkler; 2 - gas inlet pipe; 3 - gas outlet pipe; 4 - body of the vortex element; 5 - end cap; 6 - gas transition to the next stage; 7 - gas inlet to the next stage; 8 - external device box

The main elements of the vortex absorption device are: swirl, inlet pipe, box, upper and lower contact legs. The swirl is an impeller with a blank top base. The impeller is a set of bent plates located at an angle in the center of the device. 
The diameter of the experimental device under laboratory conditions is $0.35 \mathrm{~m}$ with a working height of three sections of $1200 \mathrm{~mm}$.

The vortex device operates as follows. The gas flow moves from bottom to top of the swirl through the pipe. Gas passes through the slots between the plates and exits, spinning, into the inner region between the swirl and the fluid supply pipe. In this area, the main heat and mass transfer occurs during countercurrent interaction of the gas phase with the liquid. If the vortex device is used as a splash trap, then the main phase separation occurs in this area.

The liquid enters the stage through the liquid inlet pipe. Then the liquid is distributed and evenly passes through the liquid distributor, forcibly entering the zone of vortex mass transfer under the action of centrifugal forces and the initial pressure of the liquid. In the vortex mass transfer zone, the liquid is unwound by the friction forces of the gas flow and moves in the form of a high turbulent layer.

In the upper part of the contact stage, a layer of liquid that rotates due to centrifugal forces is separated from the gas stream and enters the area of the liquid outlet to the downstream stage. The liquid flows into the switchgear, and then, after passing the lower vortex contact degree, it is gravity-fed from the device.

\section{1. Experimental procedures}

To study the mass transfer processes, the laboratory device (Fig. 1, b) was equipped with gas samplers at the outlet.

The main attention was focused on determining the dependence of the efficiency of the vortex device on the ammonia absorption on the flow rate and the ammonia concentration in the gas at the device inlet and the ammonia concentration in the liquid.

The gas flow rate of the laboratory device was studied in three modes within the range of $500-1000 \mathrm{~m}^{3} / \mathrm{h}$. The ammonia absorption by saline (brine) was investigated. The brine flow rate was $5-10 \mathrm{~m}^{3} /$ hour. The ammonia concentration in a series of experiments is from 70 to $130 \mathrm{~g} / \mathrm{m}^{3}$.

The value of the efficiency was determined according to [8] from the relation:

$$
\eta=\frac{\left(P_{\mathrm{NH}_{3}}\right)_{\text {in }}-\left(P_{\mathrm{NH}_{3}}\right)_{\text {out }}}{\left(P_{\mathrm{NH}_{3}}\right)_{\text {in }}-\left(P_{\mathrm{NH}_{3}}\right)_{\text {equal }}} \cdot 100 \%,
$$

where $\left(P_{\mathrm{NH}_{3}}\right)_{\text {in }}$ - the ammonia concentration in the gas at the inlet (in), outlet (out) and equilibrium (equal), respectively.

Mathematical processing of the experimental results was carried out using the Statistaca program.

The flows in the device were modeled using the ANSYS software package.

\section{Results}

The results of an experimental study of the ammonia absorption in a vortex device by brine are presented in Fig. 2, $\boldsymbol{a}$.

The analysis of dependencies presented in Fig. 2 shows that the absorption efficiency, and therefore the efficiency of the vortex device, depends on the ammonia concentration in the gas and the consumption of the absorber. With an increase in the ammonia concentration, the efficiency decreases as well as decreases with a decrease in the consumption of absorbent (brine).

Statistical processing of these experiments reveals the equation of the dependence of the vortex device efficiency $(\eta)$ on the ammonia concentration (C) and brine flow (Q) in the form of a second-order polynomial:

$$
\eta=97.3823-0.365 \cdot C+3.1281 \cdot Q-0.002 \cdot C^{2}+0.0428 \cdot C \cdot Q-0.2054 \cdot Q^{2} .
$$

This dependence makes it possible to calculate the predicted efficiency of the abortion, depending on the ammonia concentration at the inlet of the vortex absorber. It is also possible to calculate the required amount of absorber to absorb ammonia of a given concentration to achieve the required absorption degree. 


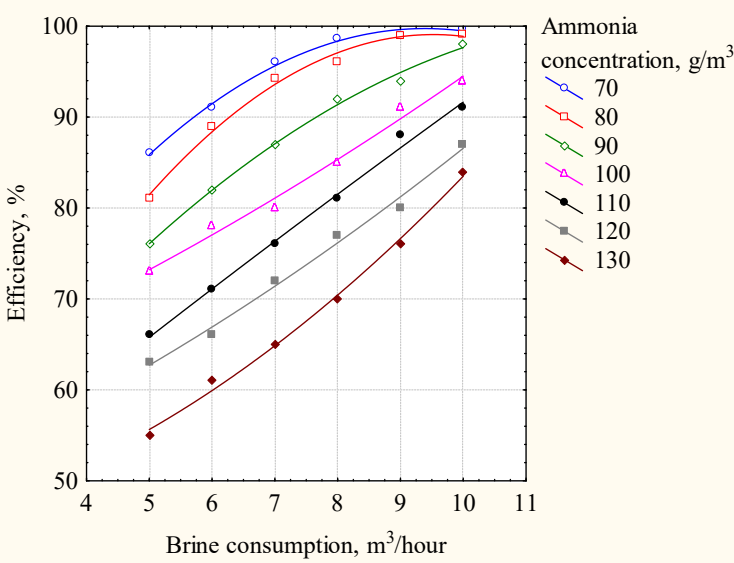

a

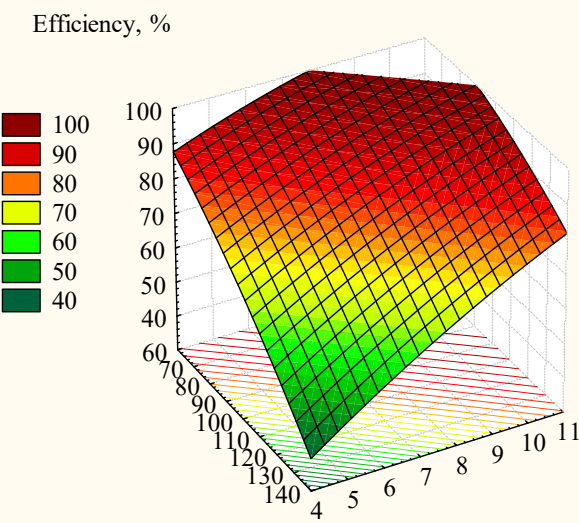

Ammonia concentration, $\mathrm{g} / \mathrm{m}^{3}$

Brine consumption, $\mathrm{m}^{3} /$ hour

$b$

Fig. 2. The dependence of the efficiency of the vortex device $(\eta)$ on the ammonia concentration (C) and the flow rate of brine (Q) at a gas flow rate of $1000 \mathrm{~m}^{3} / \mathrm{h}$ : $a$-graphical dependence; $b$ - response surface

\section{Discussion}

Let's consider the operation of the vortex device of the proposed design on the model under gas operating conditions of $1000 \mathrm{~m}^{3} / \mathrm{h}$ in the form of a dual unit (Fig. 3): radial-axial and centrifugal sections.

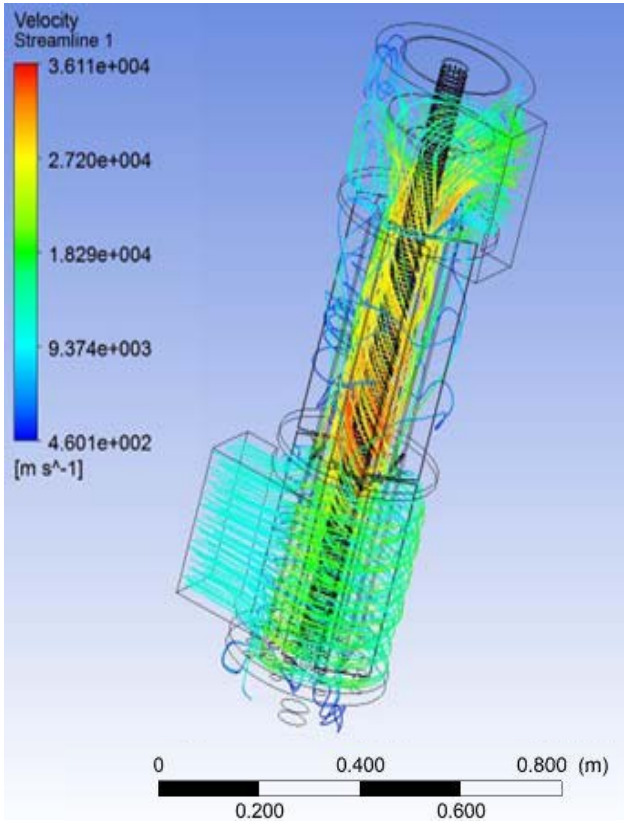

$a$

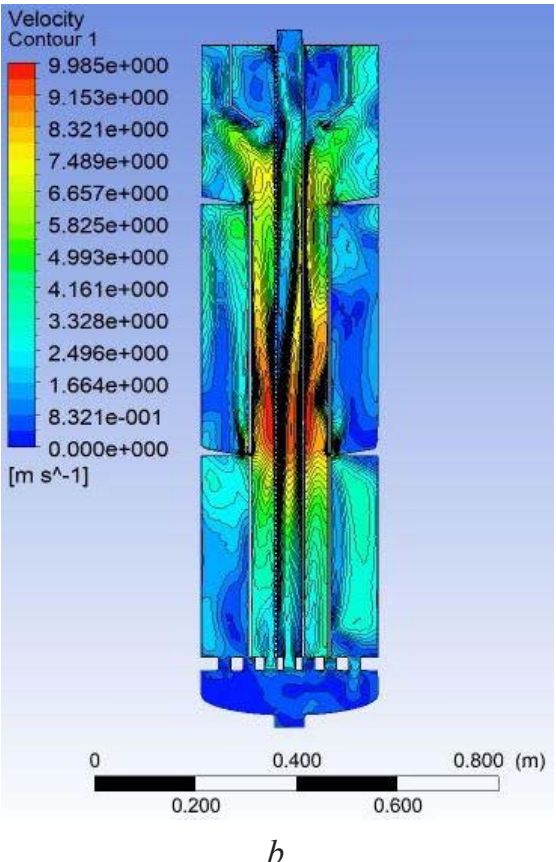

$b$

Fig. 3. Flow simulation in the device with a gas throughput of $1000 \mathrm{~m}^{3} / \mathrm{h}$ : $a$ - flow lines of the working medium; $b$ - velocity field in the device

When the working medium enters the device, due to the cochlear shape of the first section (Fig. 4, a), the flow begins to swirl (Fig. 3, a, Fig. 4, b), heading toward the center. This process is facilitated by "guides", which give the flow vector, directing it to the central pipe, thereby giving uniformity to the flow, when it is swirling to the central part. Due to this, the working medium is accelerated in the region of the center of the chamber, flow turbulization and intensive mass transfer are detected during laboratory experiments (Fig. $2, \boldsymbol{a}$ ).

In turn, the guides, in addition to accelerating the working environment, play the role of local resistances, where low pressure fields are observed in the chamber of the device. 


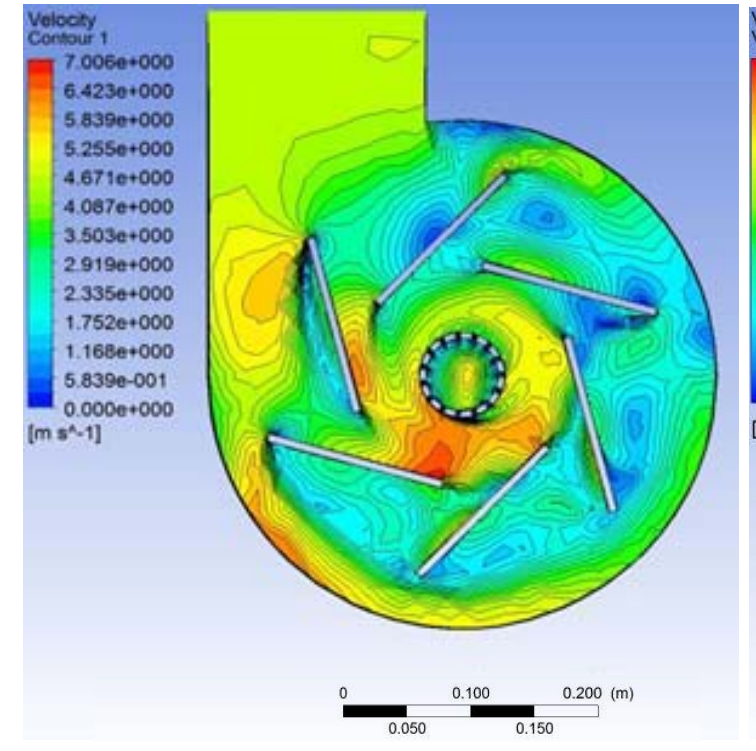

$a$

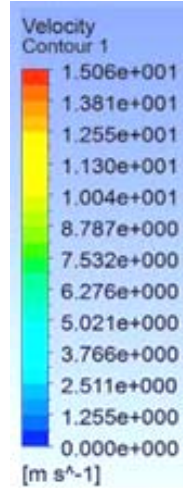

$\left[\mathrm{m} \mathrm{s}^{\wedge}-1\right]$
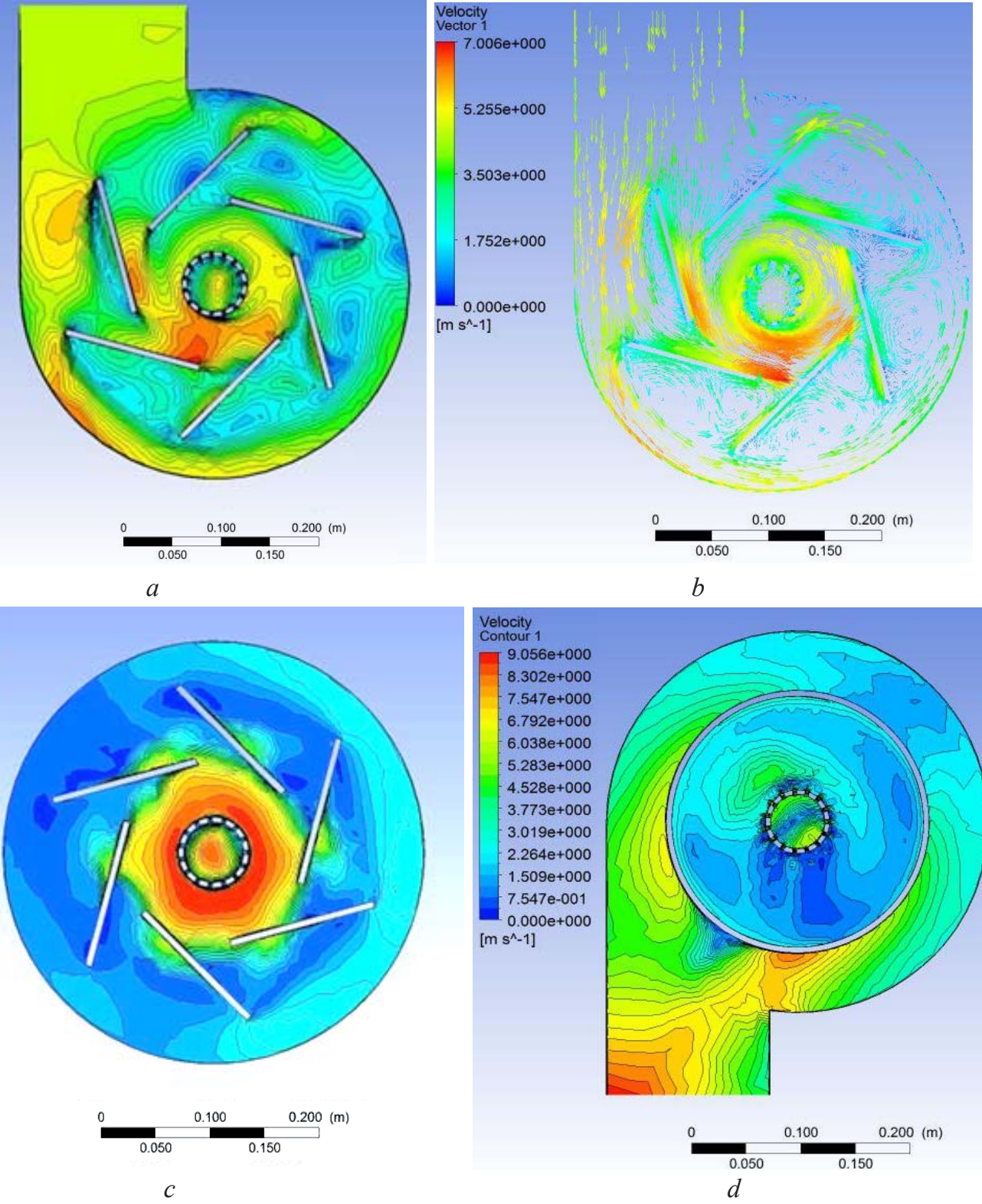

$b$

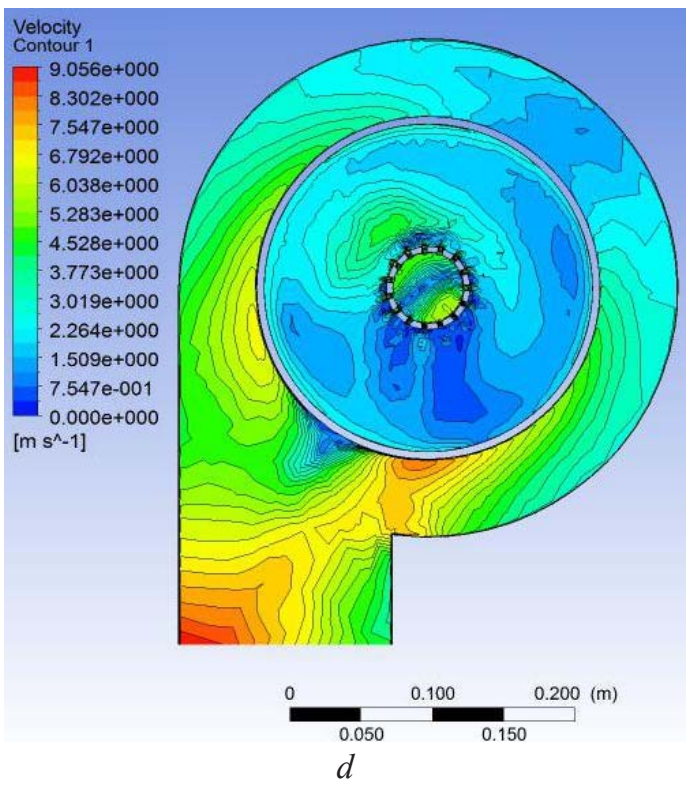

$d$

Fig. 4. Velocity field in the device section:

$a-$ on the inlet section of the device;

$b$ - flow direction in the first section; $c$ - central part of the device;

$d$ - the upper part of the device with a spray baffle and a gas outlet pipe

The movement in the second section of the device (Fig. $\mathbf{4}, \boldsymbol{c})$ is a uniform swirling movement of the working medium.

The processes (from the point of view of hydraulics) taking place in the third stage of the device (Fig. 4, $\boldsymbol{d}$ ) are diametrically opposite to those that we could observe in the first stage. Here, the flow is twisted due to all the same guides, which are mirrored to those in the first stage. The shape of the section, as well as the guides, allow the flow of the working medium to reduce vorticity, to give it a centrifugal flow vector in order to output with the least possible hydraulic losses in the last (third section) of the device.

Considering the flow patterns in this device in different gas modes $\left(500\right.$ and $\left.1000 \mathrm{~m}^{3} / \mathrm{h}\right)$, it is possible to conclude that the behavior of the working medium at various flows is similar to that for the velocity along the device height (Fig. 5).

This allows to confirm the proportionality of hydraulic losses along the working cavity of the device with an increase in the flow rate of the working medium (gas) (Fig. 6). 


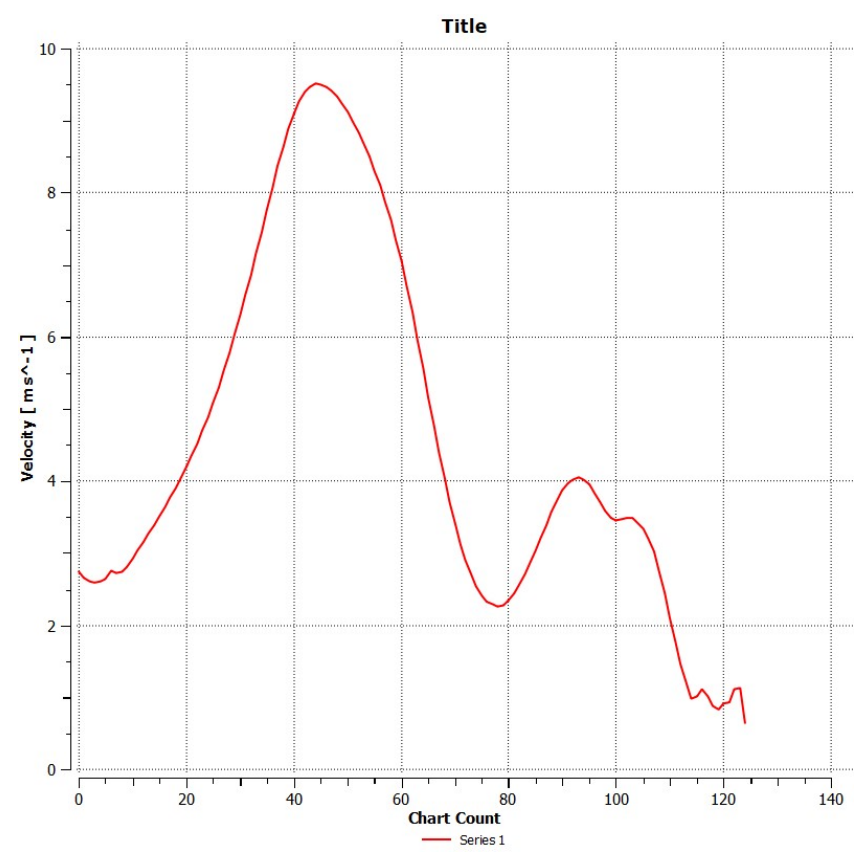

a

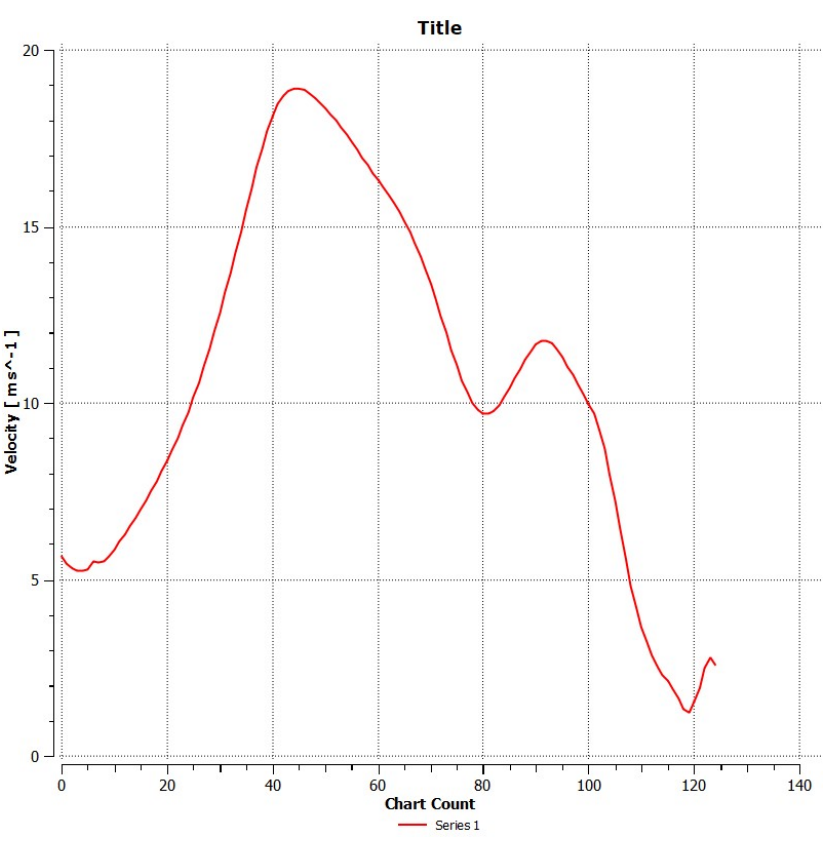

$b$

Fig. 5. Gas flow velocities along the device height (abscissa axis in $\mathrm{cm}$ ): $a$ - at a flow rate of $500 \mathrm{~m}^{3} /$ hour; $b$ - at a gas flow rate of $1000 \mathrm{~m}^{3} / \mathrm{h}$

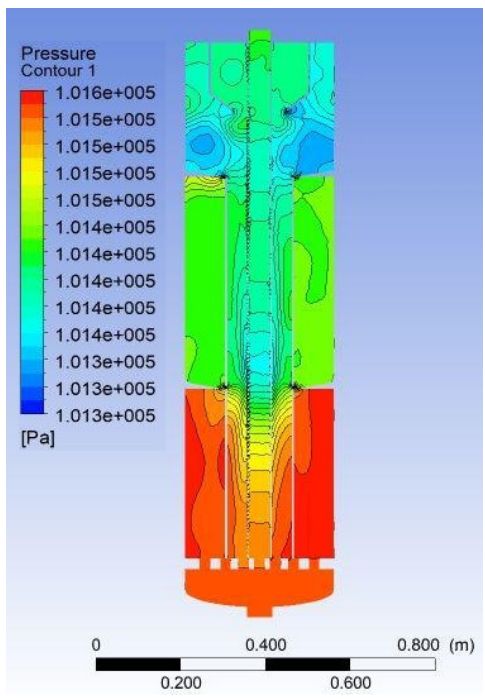

$a$

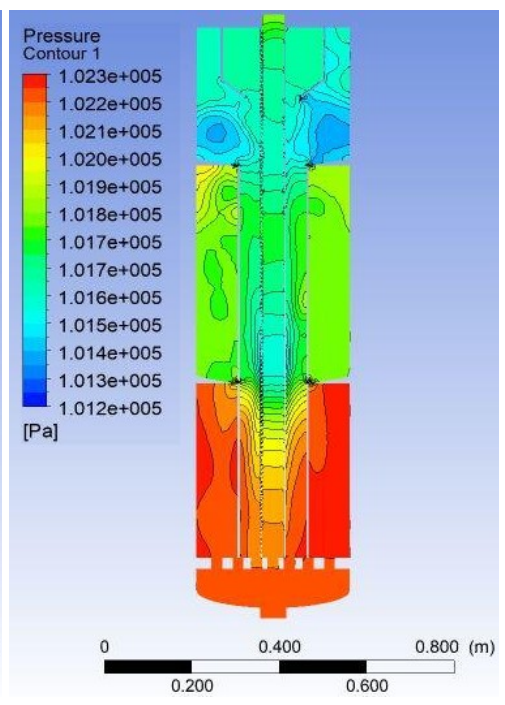

$b$

Fig. 6. Predicted pressure in the device: $a$ - at a flow rate of $500 \mathrm{~m}^{3} /$ hour; $b$ - at a gas flow rate of $1000 \mathrm{~m}^{3} / \mathrm{h}$

Thus, the developed vortex contact device is operable both at high $\left(1000 \mathrm{~m}^{3} / \mathrm{h}\right)$ and at a low gas flow rate $\left(500 \mathrm{~m}^{3} / \mathrm{h}\right)$. The axial symmetry of the vortex devices allows for a high degree of gas absorption when the gas flow rate changes to $1000 \mathrm{~m}^{3} / \mathrm{h}$.

The disadvantage of the presented results is that in laboratory conditions the efficiency of the device is checked for the ammonia absorption in only one mode - at a gas flow rate of 1000 $\mathrm{m}^{3} / \mathrm{h}$. A promising area of further research is the experimental verification in laboratory conditions of the efficiency of a vortex device at lower and higher gas productivity. It is possible that with a decrease in productivity and a decrease in the flow rate of phases, the efficiency will decrease due to a decrease in the mass transfer coefficient. But even with an increase in productivity, a loss in the efficiency of the device due to a decrease in the residence time of gas in the device is possible. These questions are the basis for further research in this direction. 


\section{Conclusions}

An improved design vortex absorption mass transfer device is proposed. The work of the vortex device for the ammonia absorption by brine is carried out, which showed its rather high efficiency (up to $99 \%$ ). The dependence of the absorption efficiency of the device on the ammonia concentration and the consumption of the absorber is established. An equation is proposed for calculating the efficiency of a vortex device depending on the ammonia concentration in the gas and the brine flow rate in the form of a second-order polynomial. This equation allows to calculate the ammonia absorption efficiency at given inputs or to calculate the consumption of the absorber to ensure a given efficiency at a given value of the ammonia concentration.

As a result of modeling processes in the device, the possibility of its operation with a productivity of $500-1000 \mathrm{~m}^{3} / \mathrm{h}$ in gas with a coefficient of efficiency sufficient for industrial conditions is analyzed.

\section{References}

[1] Kasikowski, T., Buczkowski, R., Dejewska, B., Peszyńska-Białczyk, K., Lemanowska, E., Igliński, B. (2004). Utilization of distiller waste from ammonia-soda processing. Journal of Cleaner Production, 12 (7), 759-769. doi: http://doi.org/10.1016/ s0959-6526(03)00120-3

[2] Shaporiev, V. P., Tseitlin, M. A., Raiko, V. F. et. al. (2014). Suchasni napriamy pidvyshchennia ekolohichnoi bezpeky vyrobnytstva sody. Sumy: Sumskyi derzhavnyi universytet, 246.

[3] Kasikowski, T., Buczkowski, R., Lemanowska, E. (2004). Cleaner production in the ammonia-soda industry: an ecological and economic study. Journal of Environmental Management, 73 (4), 339-356. doi: http://doi.org/10.1016/j.jenvman.2004.08.001

[4] Tseitlin, M. A., Shestopalov, O. V., Raiko, V. F. (2015). Increase of the reactivity of a low-active part of lime slurry in soda production. Eastern-European Journal of Enterprise Technologies, 6 (6 (78)), 33-39. doi: http://doi.org/10.15587/17294061.2015.55921

[5] Pitak, I., Shaporev, V., Pitak, O., Hrubnik, A., Moiseev, V. (2018). Investigation of the Process of Saturation of the Filter Liquid of Soda Production with Ammonia and Carbon Dioxide in the Production of Ammonium Chloride. Design, Simulation, Manufacturing: The Innovation Exchange, 481-488. doi: http://doi.org/10.1007/978-3-319-93587-4_50

[6] Tseitlin, M., Raiko, V., Shestopalov, O. (2020). Heat Exchange Characteristics of Trays for Concentrating Solutions in Direct Contact with Hot Gas Emissions. Design, Simulation, Manufacturing: The Innovation Exchange. Cham: Springer, $396-404$. doi: http://doi.org/10.1007/978-3-030-50491-5_38

[7] Hrubnik, A. (2018). Modern requirements for heat-exchange equipment. Constructive evolution of vortex spraying devices. Bulletin of the National Technical University «KhPI» Series: New Solutions in Modern Technologies, 16 (1292), $134-144$. doi: http://doi.org/10.20998/2413-4295.2018.16.21

[8] Sklabinskii, V. I., Al Khaiiat Mokhammed, N. K. (2014). Sanitary treatment of gas emissions from ammonia in the production of soda ash. Technology Audit and Production Reserves, 6 (1 (20)), 49-54. doi: http://doi.org/10.15587/2312-8372.2014.34785

[9] Sklabynskyi, V. Y., Al Khaiiat Mokhammed, N. K. (2010). Vykhrevie raspilyvaiushchye protyvo- tochnie massoobmennie apparaty. Intensyfykatsyia mas- soobmena. Khimichna promyslovist Ukrainy, 6 (101), 11-14.

[10] Sklabynskyi, V. Y., Al Khaiiat Mokhammed, N. K. (2011). The characteristics of Vortex spray countercurrent mass exchange device. Engineering \& technology journal, 29 (15), 3211-3223. 